
(*) Artículos 

Acta Poetica 30-2

OTOÑO

2009

\title{
¿Cómo no temblar?
}

\author{
Jacques Derrida
}

Agradecemos infinitamente a Marguerite Derrida por facilitarnos esta conferencia, publicada póstumamente en 2006, y darnos la oportunidad de publicar por primera vez en español este texto que Derrida tembló y pensó en 2004, poco antes de su muerte.*

Palabras Clave: temblor, muerte, responsabilidad

We deeply thank Marguerite Derrida for sharing with us this conference, published posthumously in 2006, and giving us the opportunity to publish for the first time in Spanish this text that Derrida trembled and thought in 2004, shortly before his death.

KeY wORDS: tremble, death, responsability.

Fecha de recepción: 06 de junio de 2010

Fecha de aceptación: 22 de julio de 2010

* Agradecemos igualmente a Mireille Calle-Gruber, quien nos ayudó a contactar a Marguerite Derrida, y a Melina Balcázar por su apoyo en este encuentro. 



\section{Jacques Derrida}

\section{¿Cómo no temblar?}

Traducción de Esther Cohen*

\section{¿Cómo no temblar?}

Hace veinte años en Jerusalén, que en la actualidad sigue siendo uno de los epicentros de los seísmos que sacuden a todo el mundo, había comenzado una conferencia con una frase en la que la sintaxis era más o menos la misma, y decía, para comenzar, "¿cómo no hablar". ${ }^{1}$

Hoy digo: cómo no temblar.

Aún antes de comenzar, y para ya no hablarles de mí, querría relatar dos pequeñas anécdotas, dos pequeñas cosas que me sucedieron (arrivées ${ }^{2}$ ) $-\mathrm{y}$ lo que sucede, si algo sucede, sucede imprevisiblemente, ya que un acontecimiento, lo que sucede, o quien llega, es siempre imprevisto-, dos acontecimientos

*Agradezco profundamente a Cristina Azuela el tiempo dedicado a discutir conmigo cada palabra del texto de Derrida. Sin su ayuda, este texto no sería el mismo.

${ }^{1}$ Cfr. J. Derrida, Comment ne pas parler. Dénégations.

${ }^{2}$ No obstante la cantidad de significados que implica el verbo arriver, (llegar, lograr, alcanzar, pasar, suceder, acontecer), he optado por traducirlo en la mayoría de los casos por "suceder". El autor juega con estos múltiples significados, pero después de una lectura atenta, considero que lo que destaca Derrida en el caso del temblor es su característica de pasividad frente al acontecimiento del temblor, del pensamiento y de la muerte. 
relacionados con el temblor: un temblor de miedo y el miedo del temblor.

Durante la guerra, en 1942-1943, por única vez en mi vida, sentí lo que llamamos físicamente, literalmente, propiamente, un temblor del cuerpo. Fue durante los bombardeos. En Argelia había bombardeos todas las noches, a menudo de aviones italianos; nos refugiábamos en casa de un vecino, y un día, recuerdo que tenía exactamente doce años, mis rodillas se pusieron a temblar de manera incontenible. Temblaba de miedo. Y después, este verano y, como se dice, por el efecto secundario de una quimioterapia, me di cuenta un día que mi mano temblaba y que no podía continuar escribiendo, ya no lograba firmar y era aterrador, en particular para alguien que consagra su vida a escribir. No temblaba de miedo, pero tenía miedo de temblar, de ese temblor que me sucedía. Entonces, se puede temblar de miedo y se puede tener miedo de temblar.

¿Cómo no temblar?

¿Cómo hacer para no temblar? Literalmente o como figura, porque esta cuestión, en apariencia estrictamente retórica, no es secundaria. Hay que explicar a la vez la posibilidad y justificación del uso (metafórico o no, catacrético o no - y la metáfora y la catacresis permiten también la comparación con los desplazamientos tectónicos, con las sorpresas que puede reservar un terreno que se desliza o un terremoto); hay que explicar, entonces, a la vez, esa posibilidad y justificación del uso (metafórico o no, catacrético o no) del sustantivo "tremor", del verbo "temblar", del adjetivo o del atributo, es decir, del sustantivo tremor, ${ }^{3}$ a saber, del trazo trazado por una mano temblorosa, del trémolo que la mano del instrumentista imprime intencionalmente, activamente, temblando sobre la cuerda del violín o del órgano, es decir, del trémolo de la voz por la cual el cantante, el orador, el sacerdote, el cantor o el rabino revelan

${ }^{3}$ En el original "t.r.e.m.b.l.é". 
la emoción, o aún más, en el código de la tipografía, de esa línea sinuosa que alterna lo grueso y lo delgado, o aún más, el nombre del árbol que llamamos "álamo temblón” (Zitterpappel en alemán), ese álamo de corteza lisa, de tronco recto cuyas hojas provistas de delgados pecíolos se estremecen con el más leve soplo; hay que, entonces, decía, explicar la posibilidad y justificar el uso de todas esas figuras más allá de su literalidad física o, más precisamente, corporal, ya sea que se trate del propio cuerpo del viviente humano o no, animal, vegetal o divino o del cuerpo o de la corteza terrestre; este último ejemplo, el del terremoto, no se reduce, trataré de mostrarlo, a un ejemplo en una serie, ya que una cierta excepcionalidad le confiere un privilegio paradójico en esta retórica embrollada.

El terremoto, el seísmo, la sacudida sísmica y sus réplicas pueden convertirse en metáforas para designar toda mutación perturbadora (social, psíquica, política, geopolítica, poética, artística) que obliga a cambiar de terreno brutalmente, es decir, imprevisiblemente. Si yo mismo he usado y abusado a menudo de esta figura o de ese léxico sísmico, lo que veo en éste, y trataré de explicarme, es algo más o distinto que una salida fácil o que una aproximación retórica.

No podemos no temblar en el momento de pensar, de escribir $\mathrm{y}$, sobre todo, de tomar la palabra, en particular cuando a falta de fuerza y de tiempo, lo hacemos de manera más o menos improvisada; y sobre todo cuando se trata de interrogarse, como a menudo estuve tentado a hacerlo en el pasado, explícitamente, literalmente, y de manera sistemática, sobre el sentido, los sentidos, los diferentes sentidos, a veces heterogéneos, así como sobre la esencia del temblor, sobre lo que quiere decir temblar.

Acabo de decir “¿cómo no temblar?” y después "no podemos no temblar". Preciso: parece que fuera preciso temblar. Se debe en el doble sentido de la necesidad o de la obligación irresistible, pero hay que hacerlo, también, en el sentido del deber, del pudor, de la decencia y de la modestia, también del valor, incluso 
ahí donde se tiembla de miedo. El "hay que" del deber, el "hay que deber y temblar": comprendo por ello que se debe aceptar la falla, el fracaso, el desfallecimiento, la "fault line" como se diría en inglés, para nombrar la línea del terreno amenazado por el terremoto $-\mathrm{y}$ falter $^{4}$ significa dudar, tartamudear, hablar con voz entrecortada - . Parece entonces que fuera preciso temblar, no escoger temblar, como por deber, sino ceder ante la necesidad del desfallecimiento, de la debilidad, abandonando toda complacencia o todo sentimiento ingenuo o inocente de tener una firme capacidad, o el dogmatismo de saber dónde se está parado, toda presunción segura acerca del temblor; no hay que hacer como si se supiera lo que quiere decir temblar, o saber lo que es verdaderamente temblar, en verdad, ya que el temblor se mantendrá siempre heterogéneo al saber, es el único saber posible al respecto. Sabemos que no sabremos jamás nada esencial al respecto, incluso si sabemos algo, incluso si podemos parlotear, discutir al respecto. El pensamiento del temblor es una experiencia singular del no-saber; y preciso aún más, después de haber dicho: "hay que temblar, no temblamos jamás lo suficiente cuando proponemos un discurso, una filosofía o una política del temblor", agrego que el temblor, si es que existe, excede todo "hay que", toda decisión voluntaria y organizada, todo deber bajo la forma de la ética, del derecho y de la política. La experiencia del temblor es siempre la experiencia de una pasividad absoluta, absolutamente expuesta, absolutamente vulnerable, pasiva ante un pasado irreversible así como ante un porvenir imprevisible.

Tiemblo entonces, pero yo mismo no estoy seguro de tener el derecho de decir y de pensar "yo tiemblo". Ni siquiera estoy seguro de que este enunciado no sea ya una falta o un desconocimiento de lo que un temblor digno de ese nombre desestabiliza, corroe desde una falla subterránea a la autoridad, corroe la

${ }^{4}$ falter en el original. El término podría relacionarse con "falla" (N. T.). 
continuidad, la identidad del "yo" y sobre todo del "yo" como sujeto, como sustancia o soporte, sostén, sustrato, fundación subterránea de una experiencia en la que el temblor no sería más que un accidente, un atributo, un momento pasajero. "Yo tiemblo" debe en principio querer decir que el "yo" mismo ya no está seguro de ser lo que es, como un cogito que acompañaría a todas mis representaciones (dirían aquí al unísono Descartes y Kant). El temblor digno de ese nombre hace temblar a un "yo" al punto en que ya no puede plantearse como el sujeto (activo o pasivo) de un temblor violento que le sucede, de un acontecimiento que lo priva de su dominio, de su voluntad, de su libertad, por lo tanto, de su derecho a la ipseidad, ya sea al poder de pensar o de decirse autoafectivamente "yo" y, como lo significa toda ipseidad, el poder a secas, al "yo puedo" a secas o al "yo puedo saber", "yo puedo decidir", "yo puedo asumir una responsabilidad que sea solamente mía y no la de otro". Temblar hace temblar la autonomía del yo, lo instala bajo la ley del otro - heterológicamente. Reconocer, como lo hago aquí, que "tiemblo", es admitir que el ego mismo no resiste a lo que lo sacude así y lo amenaza en su facultad de decir legítimamente "yo".

Es como si "yo" se pusiera a balbucir, a hablar atropelladamente, a ya no encontrar ni formar sus palabras, como si el "yo" tartamudeara, incapaz de terminar la frase autoposicional que justamente interrumpe el temblor. Entonces, lo que sucede al "yo", lo que me sucede cuando tiemblo, es que yo no tengo, ni de hecho ni por derecho, el poder de decir o de pensar "yo" o la ipseidad del "yo". Si como acabo de hacerlo, a manera de ejemplo, dijera "yo tiemblo", sería una suerte de mistificación o de ilusión trascendental, una gran estupidez, incluso si, respetando el carácter específicamente intransitivo del verbo "temblar", yo lo completara, lo determinara con la ayuda de complementos que no serían los complementos de objeto directo de un verbo transitivo. Nuestra gramática nos permite 
decir, en rigor, "hago temblar a alguien", o aún más, "alguien o alguna cosa me hace temblar" (solamente en este sentido puedo entonces ser, en efecto, sujeto, pero no en el sentido de un sujeto dueño de sí mismo, sino de sujeto sometido al temblor). Pero la gramática francesa priva al "temblar" de toda transitividad: el verbo temblar es intransitivo. No nos autoriza decir "tiemblo a alguna cosa" o "tiemblo a alguien", aunque la ley de la lengua francesa nos permita decir (complemento directo) "tiemblo de frío", "tiemblo de miedo", "tiemblo ante la catástrofe que se anuncia" o aún más y sobre todo, "tiemblo ante el otro, ante aquélla o aquél", por ejemplo: tiemblo de miedo o de temor frente a mi padre, frente a mi maestro o frente a Dios -que no está aquí, regresaré a eso. Un ejemplo entre otros, otro entre otros- . Trataré de sugerir ahora, y hasta demostrar que más allá de la tradición abrahámica que nos lega, al menos desde san Pablo a Kierkegaard, el temor o el temblor ante Dios, una suerte de quakerismo universal (el quaker es alguien que tiembla ante la palabra de Dios), sugerir pues que todo temblor de manera literal o metonímica, tiembla ante Dios, o más aún: Dios es en principio el nombre que nombra aquello ante lo que siempre temblamos, lo sepamos o no. O más aún, Dios es el nombre de todo otro que, como todo otro, y como todo otro es todo otro, hace temblar.

Desde que me enteré que nuestro amigo Édouard Glissant nos había propuesto este tema temible (que hace temblar) y que me invitaba a hablar de ello en Italia, es decir, en italiano, en todo caso por referencia a una lengua o a una poética de tradición italiana, y a hacerlo, más precisamente, en una institución italoeuropea de diseño donde no se impedía jamás asociar la música y la escritura, la pintura y la poesía, tanto artes que requieren el uso de los dedos y de la mano como artes que piensan y se piensan como una cierta experiencia de la mano; ¿me equivoqué entonces al suponer que detrás de este tema, el Paraíso no estaba lejos? (en Italia, pues, repito, y en estos lugares consagrados por 
nuestros amigos, el diseñador y pintor, Valerio y Camilla - que aúnan el diseño y la música). Quiero decir el Paraíso de Dante y esos versos del libro XIII (76-78), conocidos por todos:

Ma la natura la dà sempre scena,

Símilmente operando a l'artista

Ch' a l'abito de l'arte ha man ché trema. ${ }^{5}$

No puedo reconstruir aquí el contexto inmediato de estos versos, ni la filosofía en general, ni la filosofía del arte o la poética, ni la onto-teología implicadas por Dante en esta aserción sobre el necesario temblor de la mano de un artista que tiene, sin embargo, el hábito y la experiencia de su arte. Pero yo diría que la verdad profunda que se dice a través de estos versos de Dante es que el artista es alguien que se convierte en artista ahí donde la mano tiembla, es decir, donde él no sabe en el fondo lo que va a suceder o que aquello que va a suceder le es dictado por el otro. El momento propiamente artístico de la obra de arte es el momento en que la mano tiembla porque el artista ya no tiene el dominio, porque lo que le sucede y le sorprende como verticalmente le viene del otro. El artista no es responsable. Puede ser responsable de su saber, de su técnica, no es responsable de aquello que es lo más irreductible de su arte y que viene del otro y que hace temblar su mano. Y entonces, hay ahí, en ese temblor, una alianza de responsabilidad y de irresponsabilidad: porque el artista sabe que va a tener que asumir la responsabilidad, es decir, firmar aquello mismo de lo que no es responsable, que le viene del otro.

Temblar. ¿Qué hacemos cuando temblamos? ¿Qué es lo que hace temblar?

5 "Pero la naturaleza es siempre imperfecta, operando a semejanza del artista que posee su arte, pero le tiembla la mano". 
Un secreto siempre hace temblar. No solamente estremecerse o sentir escalofríos, cosa que sucede también alguna vez, sino temblar. El estremecimiento puede ciertamente manifestar el miedo, la angustia, la aprehensión ante la muerte, cuando nos estremecemos con anticipación frente al anuncio de lo que va a venir. Pero puede ser ligero, a flor de piel, cuando el estremecimiento anuncia el placer o el goce. Momento de pasaje, tiempo suspendido de la seducción. Un estremecimiento no es siempre muy grave, a veces es discreto, apenas sensible, un poco epifenomenal. Prepara más bien que seguir al acontecimiento. El agua, decimos, se estremece antes de hervir; es lo que llamamos la seducción: una pre-ebullición superficial, una agitación preliminar y visible.

Como en el terremoto o cuando uno tiembla con todos sus miembros, el temblor, al menos en tanto que señal o síntoma, ya tuvo lugar. Ya no es preliminar, incluso si al estremecer el cuerpo violentamente e imprimirle una tremulación incontrolable, el acontecimiento que hace temblar anuncia y amenaza de nuevo. La violencia va a desencadenarse otra vez, un traumatismo podría continuar repitiéndose. A pesar de lo diferentes que son entre ellos, el temor, el miedo, la ansiedad, el terror, el pánico o la angustia ya han comenzado en el temblor, y lo que los ha provocado continúa o amenaza con continuar haciéndonos temblar. La mayoría de las veces no sabemos y no vemos el origen - por tanto, secreto- de lo que cae sobre nosotros. Tenemos miedo del miedo, estamos angustiados por la angustia - y temblamos - . Temblamos en esta extraña repetición que une un pasado innegable. Un golpe tuvo lugar, un traumatismo nos ha afectado ya en un futuro no anticipable, anticipado pero no anticipable, aprehendido pero justamente, y por ello existe el futuro, aprehendido como imprevisible, impredecible, tan cercano como inaccesible. Incluso si creemos saber lo que va a suceder, el nuevo instante, el acontecimiento de esta llegada permanece virgen, aún inaccesible, en el fondo, invivible. En 
la repetición de lo que permanece impredecible, al principio temblamos por no saber de dónde ha venido ya el golpe, desde dónde fue dado (el buen o mal golpe, a veces el bueno al igual que el malo) y de no saber, un secreto duplicado, y de no saber si va a continuar, recomenzar, insistir, repetirse: si, cómo, dónde, cuándo. Y cuál es la razón de este golpe. Tiemblo entonces de tener aún miedo de aquello que ya me da miedo y que no veo ni preveo. Tiemblo ante lo que excede mi ver y mi saber mientras que eso me concierne hasta lo más profundo, hasta el alma y, como se dice, hasta los huesos. Dirigido hacia lo que engaña tanto el ver como el saber, el temblor es realmente una experiencia del secreto o del misterio, pero otro secreto, otro enigma $\mathrm{u}$ otro misterio viene a sellar la experiencia invivible agregando un sello o un ocultamiento de más al tremor (la palabra latina para temblor, de tremo, que en griego como en latín quiere decir tiemblo, estoy agitado por temblores; en griego también existe troméô: tiemblo, me estremezco, temo; y trómos, es el temblor, el temor, el terror. Tremendus, tremendum, como en el mysterium tremendum, en latín [adjetivo verbal de tremo] lo que hace temblar, lo aterrador, lo angustiante, lo terrorífico).

¿De dónde viene el sello suplementario? No se sabe por qué temblamos. El límite del saber ya no concierne solamente a la causa o al acontecimiento, a lo desconocido, lo invisible o ignorado que nos hace temblar. No sabemos tampoco por qué eso produce este síntoma, una cierta agitación irreprimible del cuerpo, la inestabilidad incontrolable de los miembros, este tremor de la piel o de los músculos. ¿Por qué lo incoercible toma esta forma? ¿Por qué el terror hace temblar mientras que podemos también temblar de frío, y por qué estas manifestaciones fisiológicas análogas traducen experiencias y afectos que no tienen, aparentemente al menos, nada en común? Esta sintomatología es tan enigmática como la de las lágrimas. Incluso si supiéramos por qué lloramos, en qué situación y para significar qué (lloro porque he perdido a uno de los míos, el niño llora 
porque le han pegado o porque no lo quieren: se acongoja, se queja, pide o se deja consolar), eso no explicaría sin embargo que las glándulas lagrimales comiencen a secretar esas gotas de agua que asoman a los ojos y no en otro lugar, la boca o las orejas. Habría entonces que abrir nuevas vías en el pensamiento del cuerpo, sin disociar los registros del discurso (del pensamiento, la filosofía, las ciencias bio-genético-psicoanalíticas, la filo - y la ontogénesis) para acercarse un día a lo que hace temblar o a lo que hace llorar, a esta causa que no es la causa última, que podemos llamar Dios o la muerte (Dios es la causa del mysterium tremendum, y la muerte dada es siempre lo que hace temblar o también lo que hace llorar), pero la causa más cercana, no la causa cercana, es decir, el accidente o la circunstancia, sino la causa más cercana a nuestro cuerpo, eso mismo que hace que en ese momento temblemos o lloremos en lugar de hacer otra cosa. ¿Qué es lo que se metaforiza o se figura entonces? ¿Qué quiere decir el cuerpo, suponiendo que pudiéramos aún hablar aquí de cuerpo, de decir y de retórica?

¿Qué es lo que hace temblar en el mysterium tremendum? Es el don del amor infinito, la disimetría entre la mirada divina que me ve y yo mismo que no veo aquello mismo que me mira, es la muerte de lo irremplazable dada y sobrellevada, es la desproporción entre el don infinito y mi finitud, la responsabilidad como culpabilidad, el pecado, la salvación, el arrepentimiento y el sacrificio. Al igual que el título de Kierkegaard, Temor y temblor, el mysterium tremendum comporta una referencia al menos indirecta e implícita a san Pablo.

Ahora, para ganar tiempo, paso a san Pablo.

En la epístola a los Filipenses (2:12), se pide a los discípulos que trabajen por su salvación en el temor y en el temblor. Deberán obrar para su salvación sabiendo que Dios decide: el Otro no tiene ninguna razón para darnos y ninguna cuenta que rendirnos, ni razones que compartir con nosotros. Tememos y temblamos porque estamos ya en las manos de Dios, libres sin 
embargo de trabajar, pero en las manos y bajo la mirada de Dios a quien no vemos, y de quien no conocemos ni las voluntades ni las decisiones por venir, ni las razones de querer esto o lo otro; nuestra vida o nuestra muerte, nuestra perdición o nuestra salvación. Tememos y temblamos ante el secreto inaccesible de un Dios que decide por nosotros, mientras que nosotros somos sin embargo responsables, es decir, libres de decidir, de trabajar, de asumir nuestra vida y nuestra muerte.

Pablo dice, y éste es uno de sus "adioses" de los que hablábamos:

Así pues, queridos míos, de la misma manera que habéis obedecido siempre, no sólo cuando estaba presente sino mucho más ahora que estoy ausente [ non ut in praesentia mei tantum, sed multo magis nunc in absentia mea; mè hos en tê parousía mou mónon allà nûn pollô mâllon en tê apousía mou], trabajad con temor y temblor [cum metu et tremore; metà phóbou kaì trómou] por vuestra salvación (Flp. 2:12).

Primera explicación del temor y del temblor, de ese "temor y temblor": se pide a los discípulos trabajar por su salvación no en presencia (parousía) sino en ausencia (apousía) del maestro: sin ver ni saber, sin comprender la ley o las razones de la ley. Sin saber de dónde viene todo ello y lo que nos espera, estamos abandonados a la soledad absoluta. Nadie puede hablar con nosotros, nadie puede hablar por nosotros, debemos hacernos cargo de nosotros, cada uno debe encargarse (auf sich nehmen [tomar a su cargo], decía Heidegger respecto de la muerte, de nuestra muerte, de lo que es siempre "mi muerte" y de la cual nadie puede hacerse cargo en mi lugar). Pero hay algo aún más grave en el origen de este temblor: si Pablo dice "adiós" y se ausenta demandando obedecer, al ordenar en verdad obedecer (ya que no se pide obedecer, se ordena), es porque Dios mismo está ausente, oculto y silencioso, separado, secreto - en el momento en que hay que obedecerlo- Dios no da sus razo- 
nes, actúa como él lo entiende, no tiene que dar sus razones ni compartir nada con nosotros: ni sus motivos, si es que existen, ni sus deliberaciones, ni siquiera sus decisiones. Él no sería Dios de otra manera, no tendríamos nada que ver con el Otro como Dios o con Dios como todo otro. Si el otro compartiera con nosotros sus razones explicándonoslas, si nos hablara todo el tiempo sin ningún secreto, no sería el otro, estaríamos en un elemento de homogeneidad: en la homología, es decir, en lo monológico. El discurso es también un elemento de lo Mismo. No hablamos con Dios ni a Dios; no hablamos con Dios ni a Dios como con los hombres o con nuestros semejantes. Pablo continúa, en efecto: "Pues Dios es quien obra en vosotros el querer y el obrar, como bien le parece" (Flp. 2:13).

Comprendemos que Kierkegaard eligiera, para su título, el discurso de un gran judío convertido, Pablo, en el momento de meditar sobre una experiencia también judía del Dios oculto, secreto, separado, ausente o misterioso, el mismo que, sin revelar sus razones, decide exigir de Abraham el gesto más cruel y el más imposible, el más insostenible: ofrecer a su hijo Isaac en sacrificio. Todo eso sucede en secreto. Dios guarda silencio sobre sus razones, Abraham también, y el libro no está firmado por Kierkegaard, sino por Johannes de Silentio.

Quiero una vez más hacer el salto hacia este extraño funcionamiento de la figura y de la cosa llamada terremoto. Sabemos lo que es el terremoto en sentido literal; y luego, hay un terremoto figural, por ejemplo, como lo que sucede ahora en el mundo, el seísmo que sacude la fundación misma del orden internacional, del derecho internacional, todo el mundo sufre un terremoto en la actualidad, por lo tanto el terremoto es ahí una figura.

Pero lo que querría mostrar para terminar es que el terremoto como figura no es una figura, y dice algo esencial con respecto del temblor. El terremoto como figura no es una figura entre otras. ¿Qué quiere decir esto?

Hay un texto de Celan, un poema de Celan que recientemen- 
te me interesó mucho, ${ }^{6}$ que dice "Die Welt ist fort, ich muss dich tragen": "El mundo ha partido, yo debo cargarte". ${ }^{7}$ Cuando he tratado de interpretar este verso que desde hace años me fascina, he insistido, por una parte, en el hecho de que en el momento en el que ya no existe el mundo, o que el mundo pierde su fundamento, donde ya no hay suelo - en el terremoto ya no hay suelo ni fundamento que nos sostenga- - ahí donde ya no hay mundo ni suelo, debo cargarte, tengo la responsabilidad de cargarte porque ya no tenemos apoyo, ya no puedes pisar un suelo confiable y por lo tanto tengo la responsabilidad de cargarte. $\mathrm{O}$ bien, cuando ya estás muerto $-\mathrm{y}$ es pues un pensamiento del duelo, otra interpretación-, cuando ya no hay mundo porque el otro está muerto, y la muerte es cada vez el fin del mundo, cuando el otro está muerto, debo cargarlo según la lógica clásica de Freud según la cual el llamado trabajo de duelo consiste en cargar consigo, en ingerir, en comer y en beber al muerto, para llevarlo dentro de uno. Cuando el mundo ya no existe debo cargarte, es mi responsabilidad ante ti: es pues una declaración de responsabilidad hacia el otro amado.

Pero tragen pertenece también al vocabulario de la gestación (la madre que carga en su vientre a un niño): para el niño que aún no ha nacido no existe el mundo, aún no existe mundo, y ahí, donde no hay mundo, debo cargarte. Lo que quiere decir es que ya sea que se trate de la relación de la madre con el niño o que se trate de uno al otro, de quien sea a quien sea, la responsabilidad del debo cargarte supone la desaparición, el alejamiento, el fin del mundo. No existe más responsabilidad que ahí donde se halla el fin del mundo, ahí donde ya no hay suelo, ni tierra, ni fundamento. Para ser responsable es necesario que ya no exista mundo. Entonces se puede decir: ahí donde

${ }^{6}$ Cfr. J. Derrida, Béliers. Le dialogue ininterroumpu: entre deux infinis, le poème.

${ }^{7}$ P. Celan, Große, glühende Wölbung. 
ya no hay mundo, soy responsable de ti; o bien, desde que soy responsable de ti, y te cargo, en ese mismo momento aniquilo al mundo, ya no hay mundo; en el momento en que soy responsable ante ti, el mundo desaparece. Para ser verdaderamente, singularmente responsable ante la singularidad del otro es necesario que ya no haya mundo.

\section{REFERENCIAS}

Celan, Paul, Große, glühende Wölbung, en Atemwende, Suhrkamp, Frankfurt sur Main, 1967, 93 [Renverse du souffle, trad. fr. J.-P. Lefebvre, París, Le Seuil, 2003, 113].

DANTE, Alighieri, "El paraíso", en La Divina Comedia, trad. Nicolás

González Ruiz, Madrid, Biblioteca de Autores Cristianos, 1973.

DerRIDA, Jacques, Comment ne pas parler. Dénégations en Psyché. Inventions de l'autre, Galilée, París 1987, 535-595 [Cómo no hablar. Y otros textos, trad. Patricio Peñalver, Barcelona, Proyecto "A" Ediciones, 1997].

—, Béliers. Le dialogue ininterroumpu: entre deux infinis, le poème, Galilée, París, 2003 [Carneros. El dialogo ininterrumpido: entre dos infinitos, el poema, trad. I. Agoff, Madrid/Buenos Aires, Amorrortu, 2009]. 